\title{
Effect of Thermal Treatment Temperature on Stacking Structure and Carbon Aromaticity in Coal
}

\author{
Ayumi IwAmoTo ${ }^{* 1}$, Shohei Matsuo*1, Yukinori MiYAmoto $* 1$, Yasuhiro SAITO ${ }^{* 1}{ }^{\dagger}$, \\ Yohsuke MATSUSHITA ${ }^{* 1}$, Hideyuki AoKI ${ }^{* 1}$, Yukihiro KUBOTA ${ }^{* 2}$, and Hideyuki HAYASHIZAKI*1*2
}

(Received September 27, 2017)

\begin{abstract}
To understand the properties of coking coal and coke during carbonization process, changes in stacking structure of carbon and carbon aromaticity were estimated using the XRD and NMR measurement techniques for the different four kinds of coking coals thermally treated at various temperatures. In the XRD measurement, the comparison of the diffraction patterns of the coal samples with and without decalcification indicated the proposed method could successfully eliminate peaks from ash components in the diffraction patterns. After thermal treatment, the average number of stacking layers in all the samples increased around temperature of $400-500{ }^{\circ} \mathrm{C}$ and slightly decreased around $500-700^{\circ} \mathrm{C}$. In addition, the average number of stacking layers of each sample tended to be larger for sample with higher carbon content. In the ${ }^{13} \mathrm{C}-\mathrm{NMR}$ measurement, the carbon aromaticity became larger for higher thermal treatment temperature, and the order of the carbon aromaticity almost corresponded with that of coke contraction ratio.
\end{abstract}

乾留過程に扔ける原料炭㧍よびコークスの性状を把握するために, 性状の異なる4種類の原料炭, 脱灰処理を施した原料炭お よび種々の温度で熱処理したコークスを対象に，XRD および ${ }^{33} \mathrm{C}-\mathrm{NMR}$ を用いて石炭中の炭素の積層構造と芳香族炭素分率の変 化を評価した。XRD の結果から, 提案した手法で灰分由来のピークを除去できることを示した。また, 熱処理を施すと, 平均積層 枚数は炭種によらず $400-500{ }^{\circ} \mathrm{C}$ で増加し, $500-700{ }^{\circ} \mathrm{C}$ 付近で若干減少した。さらに, 熱処理温度によらず各原料炭の炭素の平 均積層枚数は炭素含有率が高いほど多い傾向を示した。 ${ }^{13} \mathrm{C}-\mathrm{NMR}$ の結果から, 芳香族炭素分率は熱処理温度が高いほど大き な値を示した。また，高温での芳香族炭素分率の序列は収縮率とほぼ一致した。

\section{Key Words}

Coal, Heat treatment, X-ray diffraction, Solid-state nuclear magnetic resonance

\section{Introduction}

In coal which is a raw material of coke, both crystalline and amorphous exist and the crystal structure is stacking layers of carbon hexagonal net layer, which mainly consists of aromatic compound. In coke production process in which coal is heated in an inert atmosphere, the carbon hexagonal net layer is known to change ${ }^{11}$. The crystal structure is regarded as one of the factors which affect coke

\footnotetext{
※1 Department of Chemical Engineering, Graduate School of Engineering, Tohoku University 6-6-07 Aoba, Aramaki, Aoba-ku, Sendai, Miyagi 980-8579, Japan

※2 Process Research Laboratories, Nippon Steel \& Sumitomo Metal Corp. 20-1, Shintomi, Futtsu, Chiba 293-8511, Japan

†Corresponding author: saito@tohoku.ac.jp
}

properties such as reactivity ${ }^{2)}$ and true density ${ }^{3)}$. Thus, to understand coke properties, it is required to evaluate crystal structure of coke and softening coal which is a raw material of coke and to examine changes in crystal structure during carbonization process.

To evaluate crystal and chemical structure of coal and coke matrices, X-ray diffraction (XRD), Raman spectroscopy, and ${ }^{13} \mathrm{C}$ solid-state nuclear magnetic resonance (NMR) spectroscopy have been widely used. Shiraishi ${ }^{4)}$ evaluated crystal structure of softening and non-softening coals using XRD technique and reported that the layer spacing of carbon hexagonal net layer, $d_{002}$ was smaller and the average number of stacking layer was larger for coal with higher carbon content. Yoshizawa et al. ${ }^{5)}$ proposed the STAC-XRD method evaluating stacking structure with 
carbon hexagonal net layer in coal using XRD technique and Takagi et al. ${ }^{6)}$ evaluated the stacking structure of different seven coals in carbon content using the method. As a result, the trends that the average number of stacking layers of coal and char increased with an increase in carbon content and in heating rate were found. As mentioned above, the method to evaluate the stacking structure for samples with low crystallinity like coal was established. On the other hand, focusing on the methods to evaluate the chemical structure based on ${ }^{13} \mathrm{C}-\mathrm{NMR}$, Miwa et al. ${ }^{7)}$ prepared the coal chars thermally treated up to prescribed temperatures, which were similar to non-caking coal in properties, investigated the chemical structure of the carbonized chars, and concluded the value of the aromaticity rose with increasing temperature of thermal treatment and the chemical structure of samples changed. Moreover, Takeda et al. ${ }^{8)}$ investigated the size of aromatic clusters of caking and non-caking coals using ${ }^{13} \mathrm{C}$ and ${ }^{1} \mathrm{H}-\mathrm{NMR}$, and reported that the aromatic cluster size of the caking coal increased remarkably with increasing temperature from 400 to $500^{\circ} \mathrm{C}$. As mentioned above, although Yoshizawa et al. ${ }^{5)}$ and Takagi et al. ${ }^{6)}$ evaluated the stacking structure of coking coal using the XRD measurement technique, the change in the stacking structure of coking coal during carbonization process has not been investigated. In addition, although the chemical structure of carbonized char ${ }^{7)}$ and low-rank coal ${ }^{8)}$ thermally treated up to prescribed temperatures was evaluated using NMR, those samples were not coking coal. Therefore, the same coking coal sample has not been evaluated in view of the chemical and stacking structures.

In this study, four coking coals different in their properties, those with and without decalcification, and those before and after thermal treatment at various temperatures were prepared. For the prepared samples, we evaluated changes in stacking structure of carbon in coal during carbonization process by using XRD technique and eliminating peaks originated from ash components from the XRD patterns obtained. In addition, we also investigated changes in chemical structure of coal during carbonization process by evaluating aromaticity with ${ }^{13} \mathrm{C}-\mathrm{NMR}$ measurement.

\section{Experimental}

\subsection{Sample preparation}

Tables 1 and 2 list the properties of the caking coal (Coal A and Coal B), slightly-caking coal (Coal C), and non-caking coal (Coal D) used in this study. Here, coke contraction ratio in Table 1 means the volume reduction rate of coke from the temperature at which contraction starts to temperature at which carbonization completes, which was measured using the same method as the previous study ${ }^{9)}$. Each sample of about $800 \mathrm{~g}$ was pulverized into fine particles with a diameter of less than $150 \mu \mathrm{m}$ using the crusher (Wonder Blender WB-1, OSAKA CHEMICAL Co., Ltd.), which were the samples before thermal treatment. The samples of about $2 \mathrm{~g}$ were heated up to 400,500 , or $700^{\circ} \mathrm{C}$ with a heating rate of $3^{\circ} \mathrm{C}$ / min under $\mathrm{Ar}$ atmosphere using the thermogravimetry (STA449 F1 Jupiter, NETZSCH). After cooling down, the samples were pulverized into fine particles with a diameter of less than $150 \mu \mathrm{m}$ again, which were the samples after thermal treatment. In addition, each sample was treated

Table 1 Characterization of coals

\begin{tabular}{|c|c|c|c|c|c|c|c|c|}
\hline & \multicolumn{2}{|c|}{$\begin{array}{c}\text { Proximate analysis } \\
\text { [wt } \% \text { d.b.] }\end{array}$} & \multicolumn{5}{|c|}{$\begin{array}{l}\text { Ultimate analysis } \\
\text { [wt\% d.a.f.] }\end{array}$} & \multirow{2}{*}{$\begin{array}{c}\text { Coke contraction } \\
\text { ratio } \\
{[\%]} \\
\end{array}$} \\
\hline & Ash & $\mathrm{VM}$ & $\mathrm{C}$ & $\mathrm{H}$ & $\mathrm{N}$ & $\mathrm{S}$ & $\mathrm{O}_{\text {diff }}$ & \\
\hline Coal A & 10.2 & 23.7 & 89.31 & 5.02 & 2.00 & 0.57 & 3.09 & 12.69 \\
\hline Coal B & 9.1 & 25.4 & 88.89 & 5.03 & 1.61 & 0.55 & 3.93 & 14.10 \\
\hline Coal C & 5.3 & 38.5 & 84.58 & 5.44 & 2.02 & 0.36 & 7.60 & 14.78 \\
\hline Coal D & 4.3 & 42.0 & 80.04 & 5.38 & 1.81 & 0.46 & 12.31 & 16.70 \\
\hline
\end{tabular}

where VM represents volatile matter, d.b. represents dry base and d.a.f. represents dry ash free.

Table 2 Physical properties obtained by Gieseler plastometer for coals

\begin{tabular}{ccccc}
\hline & $\begin{array}{c}\text { Initial softening } \\
\text { temperature } \\
{\left[{ }^{\circ} \mathrm{C}\right]}\end{array}$ & $\begin{array}{c}\text { Maximum fluidity } \\
\text { temperature } \\
{\left[{ }^{\circ} \mathrm{C}\right]}\end{array}$ & $\begin{array}{c}\text { Resolidification } \\
\text { temperature } \\
{\left[{ }^{\circ} \mathrm{C}\right]}\end{array}$ & $\begin{array}{c}\mathrm{MF} \\
{[\text { log ddpm] }}\end{array}$ \\
\hline Coal A & 412 & 459 & 493 & 2.95 \\
\hline Coal B & 412 & 457 & 487 & 2.45 \\
\hline Coal C & 400 & 436 & 454 & 1.15 \\
\hline Coal D & - & - & - & - \\
\hline where Coal D appeared no thermoplasticity.
\end{tabular}


with hydrofluoric acid and then with hydrochloric acid, which was the sample with decalcification. The aim of decalcification of samples in this study is to distinguish the peak from ash and 002 of carbon and to validate the method to eliminate the peak from ash. The detailed procedure is as follows: The samples were immersed and stirred in hydrofluoric acid prepared to blend distilled water and hydrofluoric acid in 1:1 volume-ratio for one night, and were washed with distilled water and sodium hydroxide with concentration of $0.01 \mathrm{~N}$. The washed samples were then immersed and stirred in concentrated hydrochloric acid for one day and were again washed in the same way.

\subsection{X-ray diffraction (XRD) analysis}

The diffraction patterns of the coal samples before and after thermal treatment and with and without decalcification were measured using X-ray diffraction (SmartLab, Rigaku Corp.) and their stacking structures were evaluated. As the measurement condition, the diffraction angle of $2 \theta=20-60^{\circ}$, step interval of $0.05^{\circ}$, and measurement time of $4 \mathrm{~s}$ for each step with step scan technique were employed. Smoothing operations were then performed for the measured diffraction patterns. It is considered that the coal and coke samples in this study show not only the broad peaks originated from graphite's 002 plane but some sharp peaks from ash components. Since the stacking structure of carbon would be overestimated due to ash components with high crystalline, their peaks should be eliminated in evaluating stacking structure. In the previous studies, although the practical manner is not mentioned in detail, the peaks from ash components have been eliminated deleting arbitrary sharp peaks and interpolating diffraction intensities of before and after peaks deleted. However, the arbitrary selection of peaks from ash components can cause variation depending on researchers. Therefore, in this study, we proposed the following manner to avoid artifact in eliminating sharp peaks which were considered to be originated from ash components: The sharp peaks were detected evaluating the values of the first and second derivatives in diffraction intensity for diffraction angle and the range of the angle in which the detected peak exited was specified. The diffraction intensities in a range of the specified angle were then eliminated, and the diffraction intensities in the eliminated part were linearly interpolated between before and after the diffraction intensities. After elimination of sharp peaks considered to be originated from ash components, polarization, absorption, and atomic scattering factor were corrected and the average number of stacking layers of graphite's crystalline structure, $N_{\text {av }}$ was estimated using the method proposed by Hirsch ${ }^{10)}$.

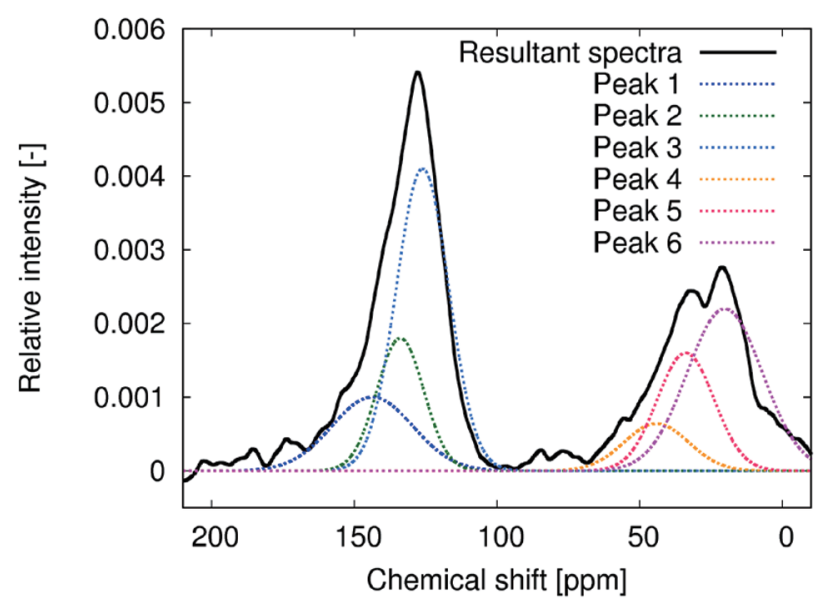

Fig. 1 CP/MAS spectra of Coal A. Solid line represents the resultant spectra and dashed lines are composed of six Gaussian and Lorentzian curves

\subsection{Solid-state nuclear magnetic resonance (NMR) analysis \\ The ${ }^{13} \mathrm{C}-\mathrm{NMR}$ spectra of the samples before and after} thermal treatment were measured using the solid-state nuclear magnetic resonance (ECA600, JEOL Ltd.) and their carbon aromaticity was calculated. As the measurement condition, the resonant frequency of $150 \mathrm{MHz}$ and cumulated number of 10000 based on the CP/MAS method were employed. Curve fitting with Gaussian and Lorentzian distribution functions and waveform separation were conducted using the analysis software (Dmfit, CEMHTI) for the measured spectra. Fig. 1 shows one of the spectra after peak split. After peak split, the peak in a range of 93$171 \mathrm{ppm}$ was identified as the one from aromatic carbon according to Yoshida et al. ${ }^{11)}$ and carbon aromaticity was calculated from its area.

\section{Results and Discussion}

\subsection{Eliminating sharp peaks from ash components in XRD pattern}

Fig. 2 shows the diffraction patterns obtained using the XRD measurement of Coal A. The pattern obtained after smoothing operation, which is drawn with a black solid line, includes several sharp peaks. The sharp peaks might be the one originated from ash components. In contrast, the pattern of the sample with decalcification with a blue solid line is rather broad and does not have any sharp peaks. Therefore, the pattern obtained after smoothing operation is found to be the one from ash components. In addition, the diffraction pattern in which the peaks were eliminated using the proposed method without artificial treatment is also indicated with a red dashed line. In the diffraction pattern (red dashed line), the proposed method has successfully 




Fig. 2 XRD patterns of Coal A: (i) smoothed pattern; (ii) pattern after eliminating sharp peaks by technique in this paper from smoothed pattern; and (iii) pattern of sample with decalcification

eliminated sharp peaks from the pattern obtained after smoothing operation (black solid line). Moreover, any sharp peaks did not appear in either the pattern in which the peaks were eliminated by the proposed method (red dashed line) nor the pattern of the sample with decalcification (blue solid line). Therefore, the proposed method in this study can eliminate undesired peaks originated from ash components in diffraction patterns in XRD measurements.

\subsection{Change in stacking structure for thermal treat temperature}

Fig. 3 indicates the average number of stacking layers, $N_{\text {av }}$ of samples before and after thermal treatment with various prescribed temperatures. At first, for the samples before thermal treatment, the $N_{\mathrm{av}}$ values of Coal $\mathrm{A}$ and Coal B are larger than those of Coal C and Coal D. The coal with higher carbon content tends to show

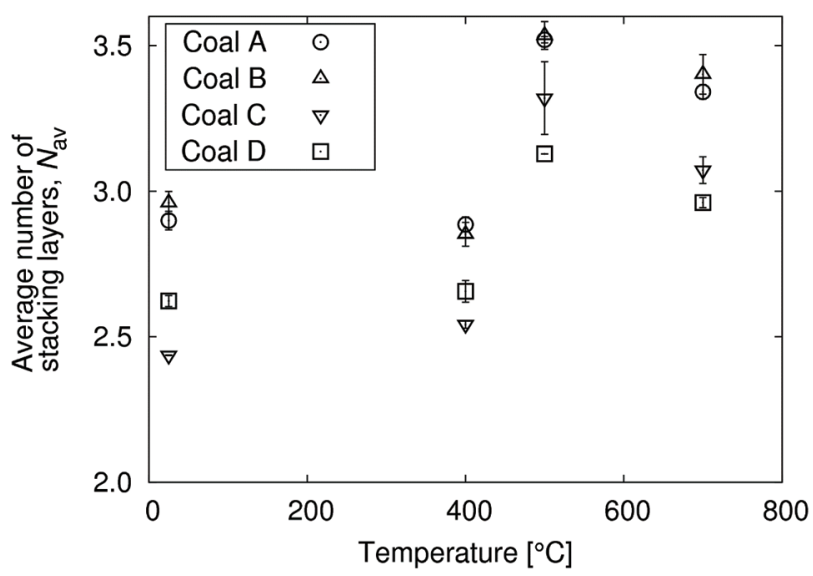

Fig. 3 The average number of stacking layers, $N_{\text {av }}$ of samples before and after thermal treatment with various prescribed temperatures (Error bars represent standard error) larger value of the average number of stacking layers. Similar to the samples before thermal treatment, for the coal samples after thermal treatment, the $N_{\text {av }}$ values of Coal A and Coal B are larger than those of Coal C and Coal D. Therefore, the stacking structure of the samples after thermal treatment is found to depend on the one of the samples before thermal treatment. Next, focusing on thermal treatment temperature, although the changes in the $N_{\text {av }}$ value is small from room temperature to $400^{\circ} \mathrm{C}$, the $N_{\text {av }}$ value drastically increased from 400 to $500^{\circ} \mathrm{C}$. The temperature range from 400 to $500^{\circ} \mathrm{C}$ corresponds to the one in which softening properties appear in Coal A, Coal B, and Coal C. Therefore, it is considered that carbon hexagonal net layers had mobility, stacking structures were developed, and the $N_{\text {av }}$ value drastically increased. However, although Coal D does not show softening property, its $N_{\text {av }}$ value also increased in the temperature range from 400 to $500{ }^{\circ} \mathrm{C}$. Futhermore, the increase rate of $N_{\text {av }}$ in Coal D is less than those in the other coal samples. The above results suggest that although Coal D does not show softening property in macro scale which can be measured using the Gieselar plastometer, it has some mobility just in micro scale in which carbon hexagnal net layers can move. Moreover, comparison of the samples after thermal treatment with temperature of 500 and $700{ }^{\circ} \mathrm{C}$ indicates the $N_{\text {av }}$ values of the samples after thermal treatment with tempearture of $700{ }^{\circ} \mathrm{C}$ were rather smaller. Yoshizawa et al. ${ }^{12)}$ showed the $N_{\text {av }}$ value of coal char produced with heating rate of $10^{2}-10^{3}$ ${ }^{\circ} \mathrm{C} / \mathrm{s}$ up to $700^{\circ} \mathrm{C}$ was smaller than that up to $500{ }^{\circ} \mathrm{C}$ and concluded that some stacking structures collapsed along with its development. Therefore, the similer phenomenon would occur in the coal samples heated with heating rate of $3{ }^{\circ} \mathrm{C} / \mathrm{min}$ in this study. Moreover, Sakanishi et al. ${ }^{13)}$ reported stacking height of carbon decreased in temperatures of 600$800^{\circ} \mathrm{C}$. Thus, the fact supports our results although their methods were different.

\subsection{Change in carbon aromaticity for thermal treatment temperature}

Fig. 4 shows the carbon aromaticity, $f_{\text {a }}$ of each coal sample with different thermal treatment temperature. In each sample before thermal treatment, the carbon aromaticity of Coal A and Coal B with higher carbon content was larger than that of Coal $\mathrm{C}$ and Coal $\mathrm{D}$. In addition, the carbon aromaticity of Coal A had larger value for higher thermal treatment temperature. As is the same with Coal A, the carbon aromaticity of the other samples also showed higher values with an increase in thermal treatment temperature. This would be because aliphatic carbons were released as volatile matter along 


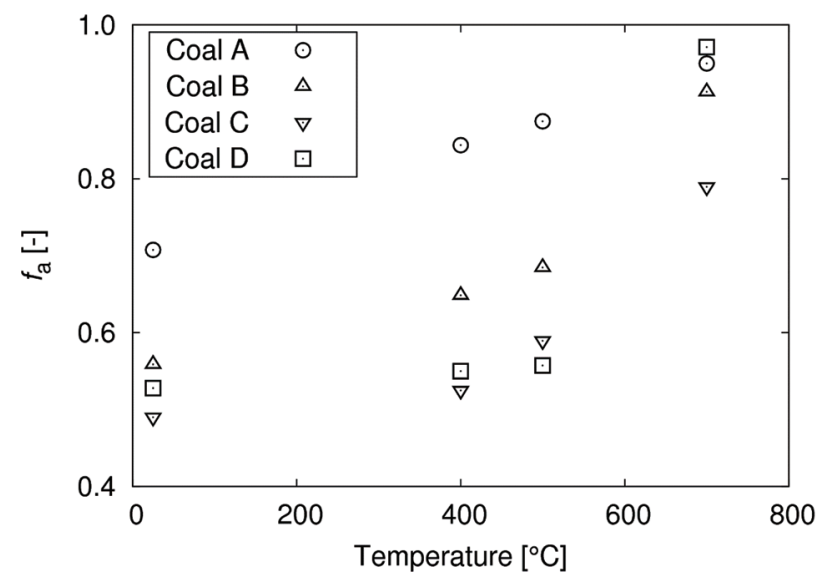

Fig. 4 The carbon aromaticity, $f_{\mathrm{a}}$ of each coal sample with different thermal treatment temperature

with carbonization process and the amount of aromatic carbons relatively increased ${ }^{14}$ ). On the other hand, for the samples treated with temperature of 500 and $700{ }^{\circ} \mathrm{C}$, their carbon aromaticity drastically incresed with an increase in thermal treatment temperature. The order in rate of increase in carbon aromaticity in range of $500-700{ }^{\circ} \mathrm{C}$ is Coal $\mathrm{D}>\mathrm{Coal} \mathrm{B} \cong \mathrm{Coal} \mathrm{C}>$ Coal $\mathrm{A}$, corresponding with the one in contraction ratio. Therefore, an increase in carbon aromaticity during carbonization process would relate with contraction phenomenon of coke.

\section{Conclusion}

In this study, four coking coals different in their properties, those with and without decalcification, and those before and after thermal treatment at various temperatures were prepared. For the prepared samples, we evaluated changes in stacking structure of carbon in coal during carbonization process by using XRD technique and eliminating peaks originated from ash components from the XRD patterns obtained. As a result, the comparison of the diffraction patterns of the coal samples with and without decalcification indicated the proposed method could successfully eliminate peaks from ash components in diffraction patterns. After thermal treatment, the average number of stacking layers in all the samples increased around the temperature of 400$500{ }^{\circ} \mathrm{C}$ and slightly decreased around $500-700^{\circ} \mathrm{C}$. In addition, the average number of stacking layers of each sample tended to be larger for the sample with higher carbon content. In addition, we also investigated changes in chemical structure of coal during carbonization process by evaluating aromaticity with ${ }^{13} \mathrm{C}-\mathrm{NMR}$ measurement. As a result, the carbon aromaticity became larger for higher thermal treatment temperature, and the order of the carbon aromaticity almost corresponded with that of coke contraction ratio.

\section{Acknowledgements}

We appreciate Dr. Noriko Yoshizawa, National Institute of Advanced Industrial Science and Technology, to kindly give us some meaningful information about eliminating peaks from ash components in diffraction patterns of the XRD measurement. The authors would like to thank Research and Development Center for Ultra High Efficiency Nano-crystalline (Tohoku University IMR) and Technical Division, School of Engineering, TOHOKU University, for their help in operating XRD and NMR measurement.

\section{References}

1) Ohtani, S.; Sanada, Y., Introduction to Carbonization Engineering, Ohmsha, Ltd., pp. 208 (1980)

2) Kashiwaya, Y.; Ishii, K., ISIJ Int., 31, 440-448 (1991)

3) Nishioka, K.; Inoue, K.; Miura, K., J. Fuel Soc. Japan, 68, 138-145 (1989)

4) Shiraishi, M., J. Fuel Soc. Japan, 64, 955-965 (1985)

5) Yoshizawa, N.; Maruyama, K.; Yamashita, T.; Akimoto, A., Proc. of 2005 Int. Conf. on Coal Sci. and Technology, 1B01, Oct. 9-13, 2005, Okinawa, Japan

6) Takagi, H.; Maruyama, K.; Yoshizawa, N.; Yamada, Y.; Sato, Y., Fuel, 83, 2427-2433 (2004)

7) Miwa, Y.; Ishida, H.; Katagiri, G., J. Jpn. Inst. Energy, 88, 102-107 (2009)

8) Takeda, N.; Zhang, L.; Kudo, S.; Hayashi, J.; Norinaga, K., Proc. 52nd Conference of Coal Science, 72, Oct. 28-29, 2015, Ise, Japan

9) Nomura, S.; Arima, T., Fuel, 105, 176-183 (2013)

10) Hirsh, P. B., Proc. Roy. Soc., London Ser. A, 226, 143-169 (1954)

11) Yoshida, T., Sekiyu Gakkaishi, 35, 1-13 (1992)

12) Yoshizawa, N.; Maruyama, K.; Yamashita, T.; Akimoto, A., Fuel, 85, 2064-2070 (2006)

13) Sakanishi, K.; Ishida, S.; Mochida, I.; Kamijo, T.; Kiguchi, J.; Honma, M., Tetsu-to-Hagane, 82, 419-424 (1996)

14） Mae, K., J. Jpn. Inst. Energy, 75, 167-177 (1996) 